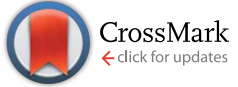

Cite this: RSC Adv., 2017, 7, 3914

Received 10th October 2016 Accepted 27th December 2016

DOI: $10.1039 / c 6 r a 24996 e$

www.rsc.org/advances

\section{Comparative synthesis and properties of POSS-based fluorinated poly(ether sulfone) random terpolymers}

\begin{abstract}
Yanfeng Wei, Qiyang Jiang, Jinmeng Hao and Jianxin $\mathrm{Mu}^{*}$
Three series of poly(ether sulfone)s are synthesized from POSS via nucleophilic aromatic substitution polycondensation with different fluoride bisphenols. The structures of the PESs are characterized by IR, NMR and WAXD spectroscopy. The incorporation of POSS and trifluoromethyl into a poly(ether sulfone) matrix at various molar percentages of POSS result in a dramatic decrease in dielectric constant, dielectric loss as well as a significant increase in hydrophobicity of the system. The lowest dielectric constant $2.23(1 \mathrm{MHz})$ is obtained at 40\% DDSQ-6FPH-PES (molar percent content of DDSQ $=40 \%$ ). The highest water contact angle $104^{\circ}$ is obtained at $20 \%$ DDSQ-6AF-PES. Dielectric loss of most synthetic polymers is lower than 0.002 . The number of trifluoromethyl groups and the attached position of these to the polymer chain also play essential roles in the dielectric properties, hydrophobicity and thermal properties. The results are discussed and interpreted in detail.
\end{abstract}

\section{Introduction}

Aromatic poly(ether sulfone)s (PESs) are well known as a class of high-performance polymers because of their outstanding properties, such as high thermal stability, high mechanical performance, good chemical resistance, and excellent electrical properties. ${ }^{1-3}$ However, as common traditional thermoplastics, PESs are poorly hydrophobic $\left(\mathrm{CA}=80^{\circ}\right)$, and the dielectric constant of PES $(\kappa=3.5)$ is not satisfactory for the demand in electronic packaging and large scale integrated circuits.

It has been reported that the introduction of bulky trifluoromethyl moieties into the polymer chains can effectively increase solubility and thermal stability, as well as decrease the dielectric constants, water absorption because of the low polarizability and large free volume of C-F bonds..$^{4-8}$ Maier et al. reported a number of polyimides incorporating trifluoromethyl groups and obtained low dielectric constant $(\kappa)$ ranging from 2.4 to $2.77 .{ }^{9} \mathrm{Liu}$ et al. demonstrated the preparation of the desired solubility and processability poly(ether ketone)s, where the bulky side group trifluoromethyl was introduced to help to decrease the dielectric constant from 3.3 to $2.69 .^{10}$ Sipra Ghosh and Susanta Banerjee employed no-planar and asymmetric trifluoromethyl moiety to poly(arylene ether)s (PAEs) to prepare gas separation polymer membranes with higher permeability and permselectivity as well as low dielectric constant values and low water absorption rates. ${ }^{11}$

However, it is limited to reduce the dielectric constants of the materials just by introducing lower molecular polarizability

College of Chemistry, The Key Lab of High Performance Plastics, Ministry of Education, Jilin University, Changchun 130012, P. R. China.E-mail:jianxin_mu@jlu.edu.cn; Fax: +86-431-88498137; Tel: +86-431-8849813 bulky trifluoromethyl moiety. In view of the dielectric constant of air ( $\kappa=1.01)$, polyhedral oligomeric silsesquioxane (POSS), as a kind of organic-inorganic nanoporous materials, has attracted attention in preparation to decrease dielectric constant. POSS possesses a cubic octameric molecule with an inner inorganic silicon and oxygen framework, which is externally surrounded by organic functions. ${ }^{12-14}$ POSS-based hybrids have been widely studied in many other areas of potential applications, ${ }^{15-20}$ such as optical devices, sensors, barrier materials and catalysts. POSS has been incorporated in polymer matrices, either physical blending or chemical copolymerization, to modify the basic properties of the system. ${ }^{21-24}$ Double-decker silsesquioxane (DDSQ) $)^{25-29}$ is a kind of admirable POSS with two precise reactive functional groups, which can be applied to synthesize linear and regularity distribution hybrid polymers by incorporating high content of POSS into the main chain.

In this work, three series of new aromatic poly(aryl ether sulfones) (PESs) were prepared from 2OH-DDSQ, difluorophenyl sulfone and three bisphenols containing trifluoromethyl groups, via the nucleophilic aromatic substitution polymerization. The effect of POSS content, the number of trifluoromethyl and the attached position of trifluoromethyl to the chain of polymer on the dielectric property, hydrophobicity and thermal property of the polymers are investigated in this work.

\section{Experimental}

\section{Materials}

2OH-DDSQ was synthesized in our laboratory according to the literature. ${ }^{25}$ (3-Fluoromethylphenyl)-1,4-hydroquinone (3FPH), and (3,5-difluoromethylphenyl)-1,4-hydroquinone (6FPH) were 
prepared according to a reported procedure. ${ }^{30} 4,4^{\prime}$-(Hexafluoroisopropylidene)diphenol was synthesized in Jilin University. Poly(ether sulfone)s was synthesized in Jilin University. Anhydrous magnesium and anhydrous calcium chloride were purchased from Guangdong Xilong Chemical. Triethylamine (AR) was purchased from Tianjin Fuyu Fine Chemical. Tetrahydrofuran (THF) (AR) was purchased from Tianjin Tiantai Fine Chemicals and was refluxed above sodium and then distilled before use. Phenyltrimethoxysilane was purchased from Energy Chemical and was immediately used upon receipt. Toluene (AR), chloroform (AR), sodium hydroxide (AR), potassium carbonate (AR), $N, N$-dimethylacetamide (DMAc; AR), dimethyl sulphoxide (DMSO; AR), and 2-propanol (AR) were purchased from Beijing Chemical Works. N-Methyl-2-pyrrolidinone (NMP; AR) was purchased from Tianjin BODI chemicals. NMP was further purified by distillation under reduced pressure over $\mathrm{CaH}_{2}$ prior to use.

\section{Measurements}

IR spectra ( $\mathrm{KBr}$ pellets or films) were recorded on a Nicolet Impact 410 Fourier Transform Infrared Spectrometer (FT-IR) at room temperature $\left(25{ }^{\circ} \mathrm{C}\right) .{ }^{1} \mathrm{H}$ NMR spectra were conducted by a Brüker Advance 300 spectrometer (300 MHz) in DMSO. Differential Scanning Calorimetry (DSC) analysis were performed on a TA Instruments Q2000 in a dry nitrogen atmosphere at a heating rate of $10{ }^{\circ} \mathrm{C} \mathrm{min}^{-1}$. Thermogravimetric analysis (TGA) was measured with a Perkin Elmer Pryis 1 TGA thermal analyzer under air atmosphere at a heat of rate $10{ }^{\circ} \mathrm{C}$ min. Dielectric constants were carried out a HewlettPackard 4285A precision impedance analyzer at frequency varied from $10^{3} \mathrm{~Hz}$ to $10^{6} \mathrm{~Hz}$. Contact angles were determined with a POWEREACH/JC2002C2 contact angle meter at room temperature $\left(25^{\circ} \mathrm{C}\right)$. Contact angles were measured on $1 \mu \mathrm{L}$ of wetting liquid, immediately after each droplet was added. The reported values are the average of six measurements from five droplets with separate locations. The crystallization behavior of the copolymers were examined by a Rigaku D/max-2500 X-ray diffractometer with $\mathrm{Cu} \mathrm{K} \alpha$ radiation $(\lambda=0.154 \mathrm{~nm})$ as the X-ray source.

\section{Polymer synthesis}

Synthesis of DDSQ-6AF-PESs copolymers. In a typical experiment, the preparation of PES-2c II (molar percent content of DDSQ $=20 \%$ ) copolymer, to a $25 \mathrm{~mL}$ three-necked flask equipped with over-head mechanical stirrer, a Dean-Stark trap with condenser, 2OH-DDSQ $(0.7411 \mathrm{~g}, 0.5 \mathrm{mmol})$, bisphenol AF (0.6725 g, $2.0 \mathrm{mmol})$, difluorophenyl sulfone (0.6356 g, $2.5 \mathrm{mmol})$, anhydrous $\mathrm{K}_{2} \mathrm{CO}_{3}(0.4146 \mathrm{~g}, 3.0 \mathrm{mmol})$, DMAc $(6.1 \mathrm{~mL})$, and toluene $(4 \mathrm{~mL})$ were added. The system was allowed to reflux for $3 \mathrm{~h}$, and then ensured that a substantial amount of the resulting water and toluene were removed. The reaction mixture was heated to $160-170{ }^{\circ} \mathrm{C}$. After $5 \mathrm{~h}$, the viscous solution was then poured into distilled water. The flexible threadlike polymer was pulverized into powder using a blender. The polymer was then refluxed in deionized water and ethanol several times to remove the salts and solvents and dried at
$120{ }^{\circ} \mathrm{C}$ for $24 \mathrm{~h}$ to obtain a constant weight. The inherent viscosity of the polymer obtained was $0.86 \mathrm{dL} \mathrm{g}^{-1}$, determined at a concentration of $0.5 \mathrm{~g} \mathrm{dL}^{-1}$ in DMAc at $25{ }^{\circ} \mathrm{C}$.

IR $\left(\mathrm{cm}^{-1}\right): 1285(\mathrm{~S}=\mathrm{O}), 1223$ (Ar-O-Ar), $1325\left(-\mathrm{CF}_{3}\right), 1253$, 828 (Si-C), 1087, 482 (Si-O-Si).

Synthesis of DDSQ-3FPH-PESs copolymers. Bisphenol AF was replaced by $3 \mathrm{FPH}$, the DDSQ-3FPH-PESs copolymers were prepared in a similar procedure.

IR $\left(\mathrm{cm}^{-1}\right): 1291(\mathrm{~S}=\mathrm{O}), 1230$ ( $\left.\mathrm{Ar}-\mathrm{O}-\mathrm{Ar}\right), 1332\left(-\mathrm{CF}_{3}\right), 1253$, 828 (Si-C), 1087, 482 (Si-O-Si).

Synthesis of DDSQ-6FPH-PESs copolymers. DDSQ-6FPHPESs were prepared from 2OH-DDSQ, 6FPH and difluorophenyl sulfone, according to the same procedure used for 6AF-DDSQ-PESs.

IR $\left(\mathrm{cm}^{-1}\right): 1285(\mathrm{~S}=\mathrm{O}), 1230(\mathrm{Ar}-\mathrm{O}-\mathrm{Ar}), 1325\left(-\mathrm{CF}_{3}\right), 1253$, 828 (Si-C), 1087, 482 (Si-O-Si).

\section{Results and discussion}

\section{Polymer synthesis}

Polymerization of 2OH-DDSQ, difluorophenyl sulfone and three different fluoride bisphenol was carried out in the presence of $\mathrm{K}_{2} \mathrm{CO}_{3}$ in DMAc as the solvent at $170{ }^{\circ} \mathrm{C}$ after removing water from the reaction system by the azeotropic distillation of toluene, as shown in Scheme 1. The inherent viscosities of the resulting polymers ranged from 0.71 to $0.91 \mathrm{dL} \mathrm{g}^{-1}$ in determined at a concentration of $0.5 \mathrm{~g} \mathrm{dL}^{-1}$ in DMAc at $25{ }^{\circ} \mathrm{C}$ (Table 1).

The chain structure of the polymers was confirmed by FTIR and NMR spectra. The FTIR spectra (Fig. 1) of the polymer films show the characteristic absorption bands around $1285 \mathrm{~cm}^{-1}$ due to sulfonyl groups, around $1230 \mathrm{~cm}^{-1}$ based on aryl ether linkages, and $1325 \mathrm{~cm}^{-1}$ corresponding to trifluoromethyl moieties. $1253 \mathrm{~cm}^{-1}, 828 \mathrm{~cm}^{-1}$ can be assigned to $\mathrm{Si}-\mathrm{C}$ band and $1087 \mathrm{~cm}^{-1}, 482 \mathrm{~cm}^{-1}$ can be attributed to $\mathrm{Si}-\mathrm{O}$ band of the DDSQ. From the comparison with IR spectra of polymers, DDSQ is confirmed to have been introduced into the main chains of the PESs polymers by covalent bonds successfully. The characteristic absorption peaks at $1087 \mathrm{~cm}^{-1}, 482 \mathrm{~cm}^{-1}\left(\nu_{\text {as }}, \mathrm{Si}-\mathrm{O}\right)$ manifest that the structure of the DDSQ macromer remains intact.

In the ${ }^{1} \mathrm{H}$ NMR spectra of the polymers, signals of proton at 0.20 ppm, 0.71-2.46 ppm and $3.53 \mathrm{ppm}$ are assigned to the protons of methyl, methylene, and methoxy. The peaks at 6.2$8.2 \mathrm{ppm}$ are assigned to the protons of aromatic ring. A typical set of NMR spectra is shown in Fig. 2, and the spectra agreed with the proposed polymer structure.

The crystallinity of the PESs was evaluated by wide angle X-ray diffraction (WAXD) (Fig. 3). All the polymers exhibited amorphous patterns. DDSQ-3FPH-PESs provide two major diffraction peaks at values of $2 \theta$ of $7.18^{\circ}$ and $19.29^{\circ}$, corresponding to $d$-spacings of $1.23 \mathrm{~nm}$ and $0.46 \mathrm{~nm}$, respectively; ${ }^{31,32}$ first is consistent with the size of a POSS unit and it is produced by the crystal structure of the POSS units, ${ }^{33}$ where a $d$-spacing of $0.46 \mathrm{~nm}$ is the average distance of PES segments. DDSQ-6FPH-PESs provide two major diffraction peaks at values of $2 \theta$ of $7.18^{\circ}$ and $17.04^{\circ}$, corresponding to $d$-spacings of $1.23 \mathrm{~nm}$ and $0.52 \mathrm{~nm}$, respectively. 


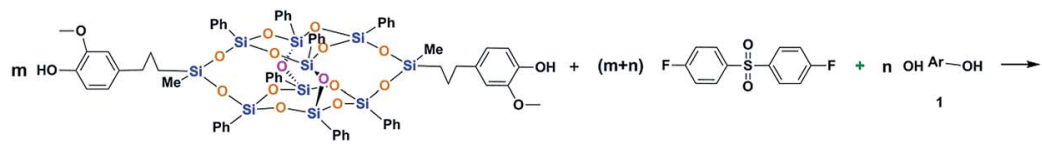

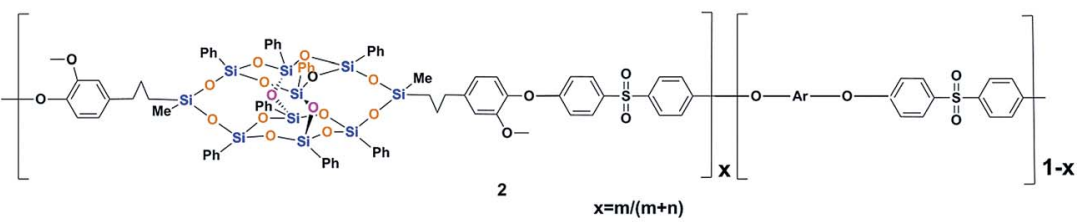

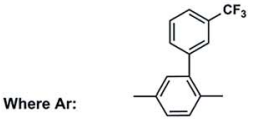

a

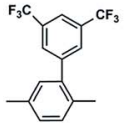

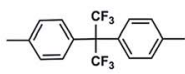

C

Scheme 1 Synthesis of DDSQ-CF3 - PESs hybrids.

Table 1 Summaries of the properties of the DDSQ-3FPH-PESS

\begin{tabular}{lllllll}
\hline Samples & $\begin{array}{l}\text { Inherent } \\
\text { viscosity }^{a}\left(\mathrm{~g} \mathrm{dL}^{-1}\right)\end{array}$ & $\begin{array}{l}T_{\mathrm{d5}}{ }^{b} \\
\left({ }^{\circ} \mathrm{C}\right)\end{array}$ & $\begin{array}{l}\text { Residue }^{d} \\
(\%)\end{array}$ & $\begin{array}{l}T_{\mathrm{g}}{ }^{d} \\
\left({ }^{\circ} \mathrm{C}\right)\end{array}$ & $\begin{array}{l}\text { CA } \\
(\mathrm{deg})\end{array}$ & $\begin{array}{l}\text { Dielectric } \\
\text { constant }^{e}\end{array}$ \\
\hline PES & 0.95 & 513.2 & 2.65 & 230 & 80 & 3.5 \\
PES 2a I & 0.75 & 539.9 & 1.49 & 156.4 & 82.9 & 3.42 \\
PES 2a II & 0.78 & 423.7 & 18.19 & 148.5 & 96.6 & 3.32 \\
PES 2a III & 0.73 & 423.9 & 18.43 & 144.9 & 98.4 & 2.82 \\
PES 2a IV & 0.72 & 418.2 & 34.29 & 142.9 & 98.7 & 2.78 \\
PES 2a V & 0.71 & 418.8 & 35.09 & 138.7 & 97.8 & 0.014 \\
PES 2a VI & 0.71 & 375.7 & 36.55 & 137 & 97.5 & 2.72 \\
loss
\end{tabular}

${ }^{a}$ Determined at a concentration $0.5 \mathrm{~g} \mathrm{dL}^{-1}$ in DMAc at $25^{\circ} \mathrm{C} .{ }^{b}$ Temperature at which $5 \%$ weight loss was recorded by thermogravimetry at a heating rate of $10^{\circ} \mathrm{C} \mathrm{min} \mathrm{in} \mathrm{air.}{ }^{c}$ The yields of degradation residues were obtained at $800^{\circ} \mathrm{C}$ in air. ${ }^{d}$ DSC at a heating rate of $10^{\circ} \mathrm{C}$ min ${ }^{-1}$ in nitrogen. ${ }^{e} \mathrm{~K}$ was measured at $1 \mathrm{MHz} .{ }^{f}$ Dielectric loss was measured at $1 \mathrm{MHz}$.

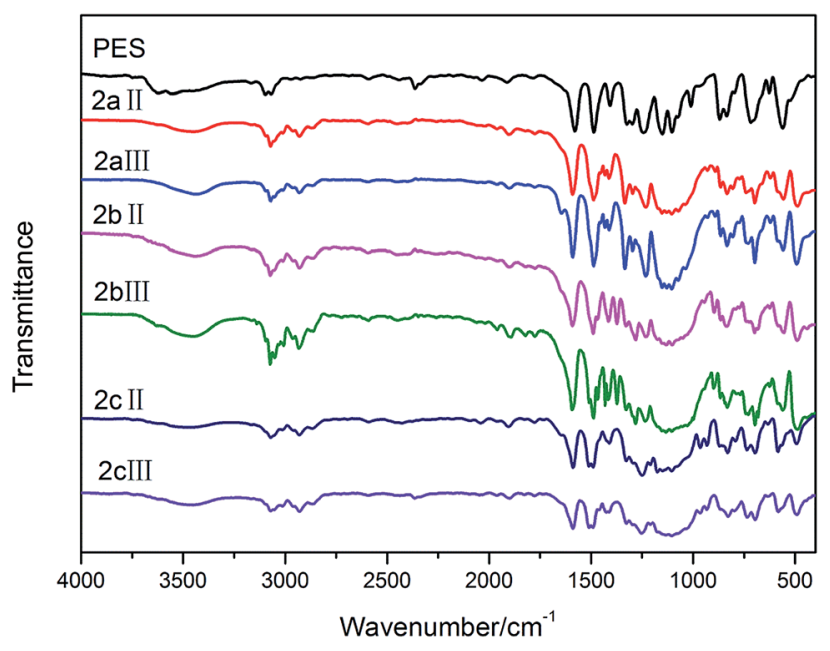

Fig. 1 FT-IR spectrum of DDSQ-CF - PESs hybrids.

DDSQ-6AF-PESs provide two major diffraction peaks at values of $2 \theta$ of $7.18^{\circ}$ and $18.89^{\circ}$, corresponding to $d$-spacings of $1.23 \mathrm{~nm}$ and $0.47 \mathrm{~nm}$, respectively.
The diffuse peak at $7.18^{\circ}$ indicates that the DDSQ molecules still retain their nanoscale dimensions in the polymer main chains. The broad peaks demonstrate that there is no crystalline behavior in the polymers, this is ascribed that DDSQ is homogeneous dispersion in the resulting nanocomposite films. The peak intensity at $7.18^{\circ}$ was enhanced and half peak width at $7.18^{\circ}$ became narrow along with the content of DDSQ increasing, indicating that the chain regularity is strengthened with the content of DDSQ increasing.

\section{Dielectric constant of polymers}

The dielectric constants $(\kappa)$ of polymer films are shown in Fig. 4. The dielectric constants of all the PESs containing trifluoromethyl or POSS is lower than pure PES ( 3.5 at $1 \mathrm{MHz}$ ).

Comparing three kinds of polymers, the dielectric constants at the same content of DDSQ represented the following law: DDSQ-3FPH-PESs > DDSQ-6AF-PESs > DDSQ-6FPH-PESs. Due to the larger free volume, lower polarity and lower moisture absorption of the trifluoromethyl groups, the introduction of trifluoromethyl into the polymers could decrease the dielectric constants. The trifluoromethyl content of the DDSQ-3FPH- 

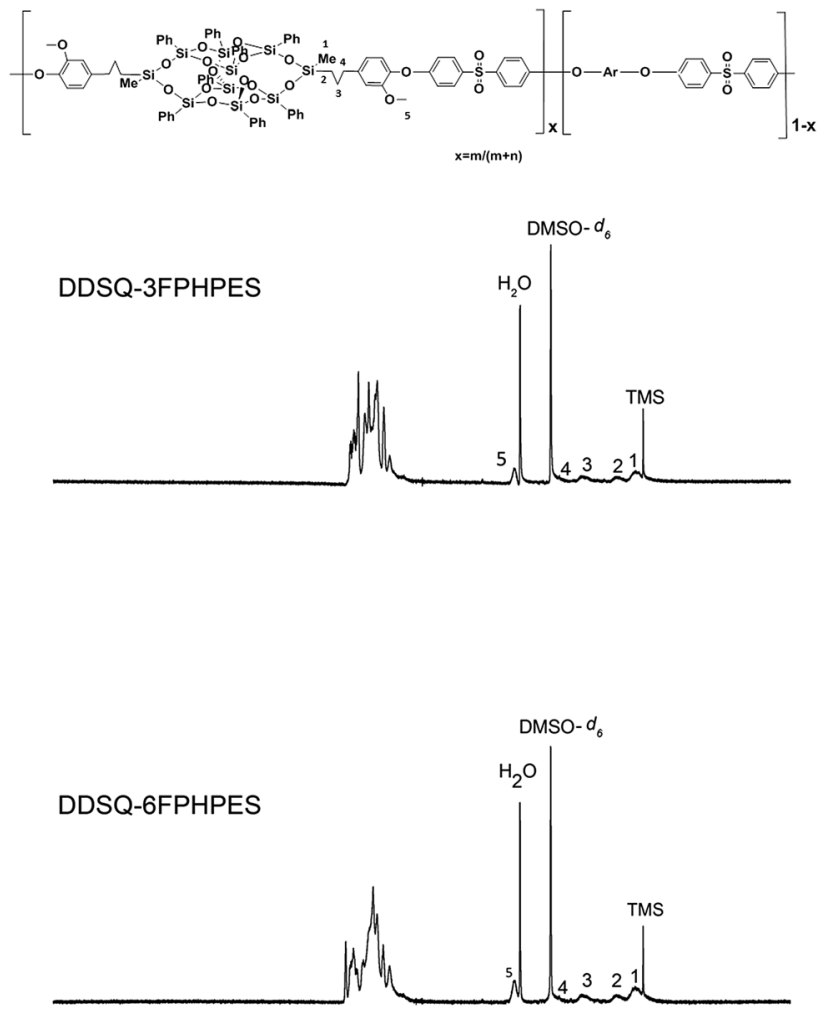

DDSQ-6AF-PES

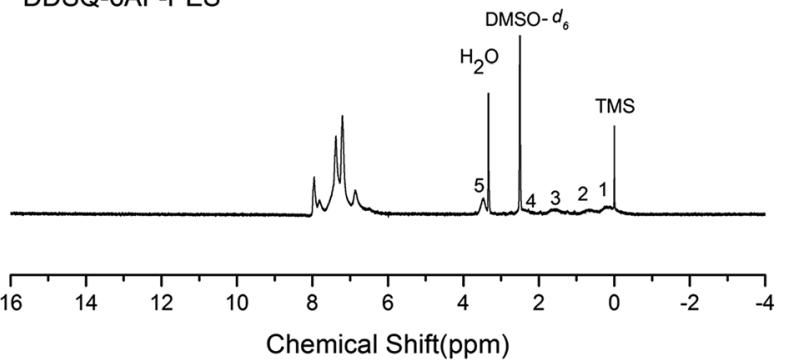

Fig. $2{ }^{1} \mathrm{H}$ NMR spectra of DDSQ $-\mathrm{CF}_{3}-\mathrm{PESs}$ hybrids in DMSO- $\mathrm{d}_{6}$.

PESs is lower than DDSQ-6FPH-PESs and DDSQ-6AF-PESs, thus has the relatively high dielectric constants. The free volume of hexafluoroisopropyl group is smaller than bulky trifluoromethyl side group, therefore the $\kappa$ values of DDSQ-6AFPESs are higher than DDSQ-6FPH-PESs. The experimental results of XRD can also confirm this conclusion.

Due to the vacant cage-like structure of DDSQ itself, the introduction of DDSQ can reduce the dielectric constant by increasing the free volume; due to the large bulky and low polarity of the trifluoromethyl itself, the introduction of trifluoromethyl can also reduce the dielectric constant. The dielectric constant of PESs which were introduced into the trifluoromethyl and POSS was significantly lower than that of the traditional PESs.

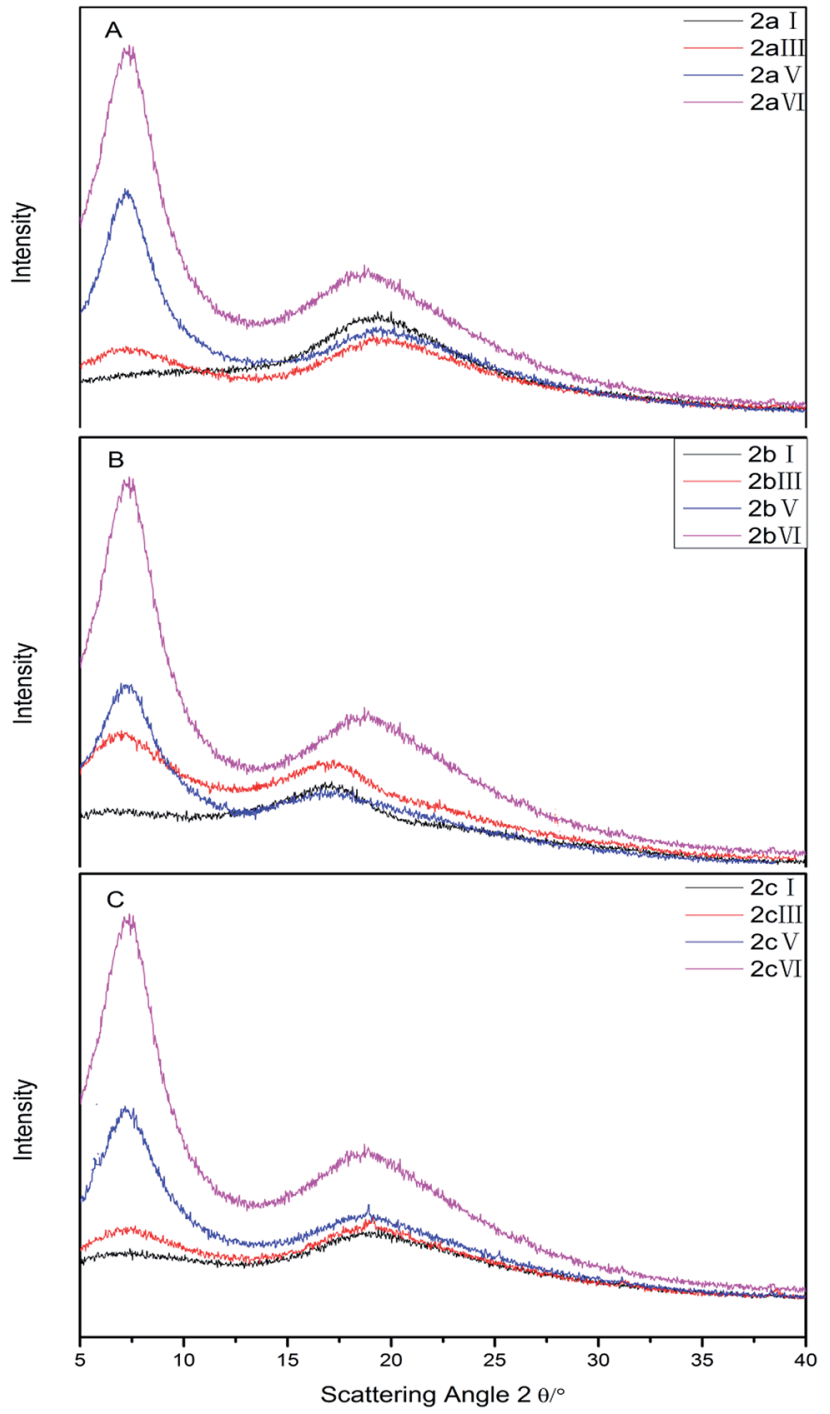

Fig. 3 WAXRD profiles of DDSQ- $\mathrm{CF}_{3}-\mathrm{PESs}$ hybrid films.

Under the synergy of trifluoromethyl and POSS, the dielectric constant of DDSQ-3FPH-PESs and DDSQ-6AF-PESs decreased gradually along with the content of DDSQ in the main chain increasing. Due to the presence of trifluoromethyl and higher POSS content simultaneously, the lowest dielectric constant was obtained at $80 \%$ DDSQ-6AF-PES. Generally, the dielectric constant of DDSQ-6FPH-PESs decreased first and then increased as the content of POSS increased, the lowest $\kappa$ value was obtained at $40 \%$ DDSQ-6FPH-PES. This can be attributed that the dielectric constant can be decreased by the combined consequences of bulky ditrifluoromethyl and POSS and the reduction of the dielectric constant of the bulky ditrifluoromethyl lateral group is larger than that of the POSS.

The dielectric loss of all synthetic copolymers is lower than 0.002 except $0 \%$ DDSQ-6FPH-PES (0.013), 60\% DDSQ-6FPHPES (0.003) and 100\% DDSQ-PES (0.022) at $1 \mathrm{MHz}$. This type of polymers is a potential candidate for electronic packaging and large scale integrated circuit. 

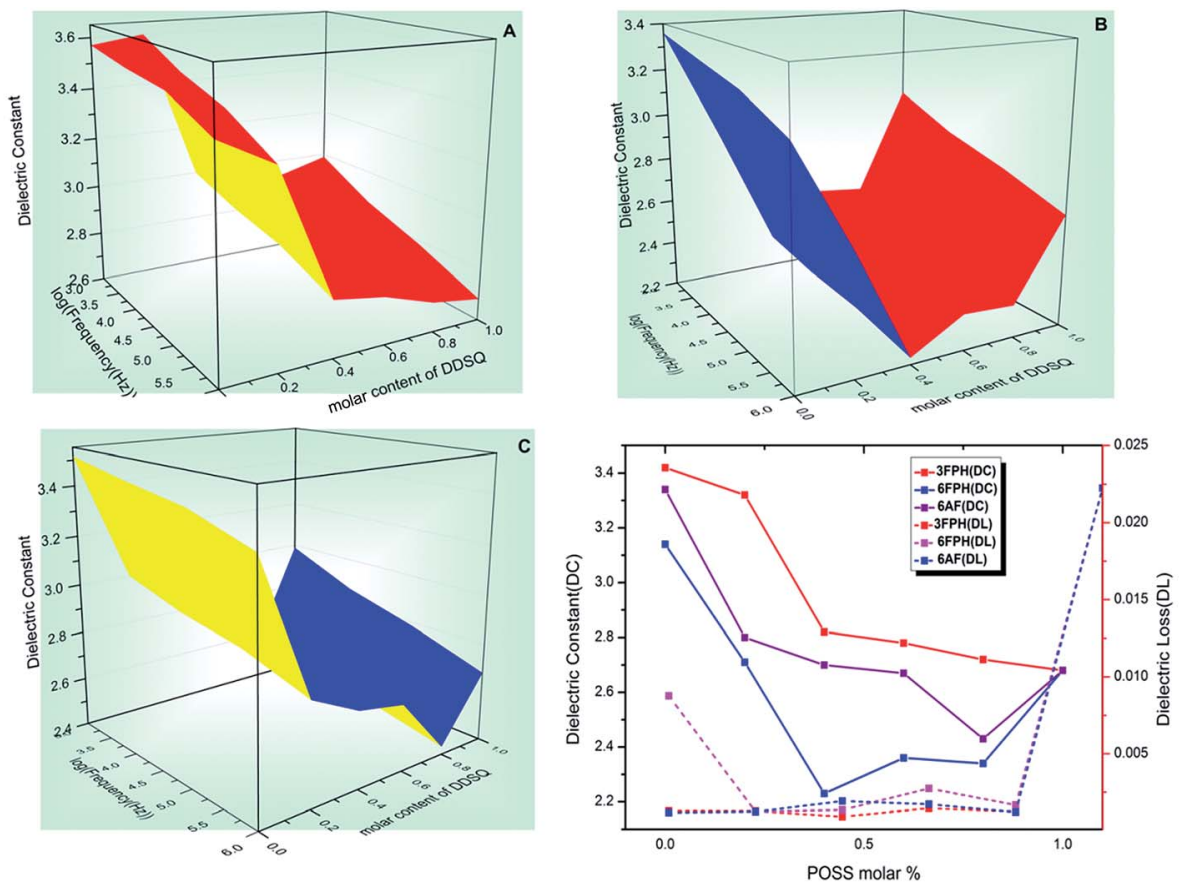

Fig. 4 The dielectric constant vs. frequency and molar content of DDSQ for PESs $2 a(A), 2 b(B), 2 c(C)$; the dielectric constant and dielectric loss vs. POSS molar\%.

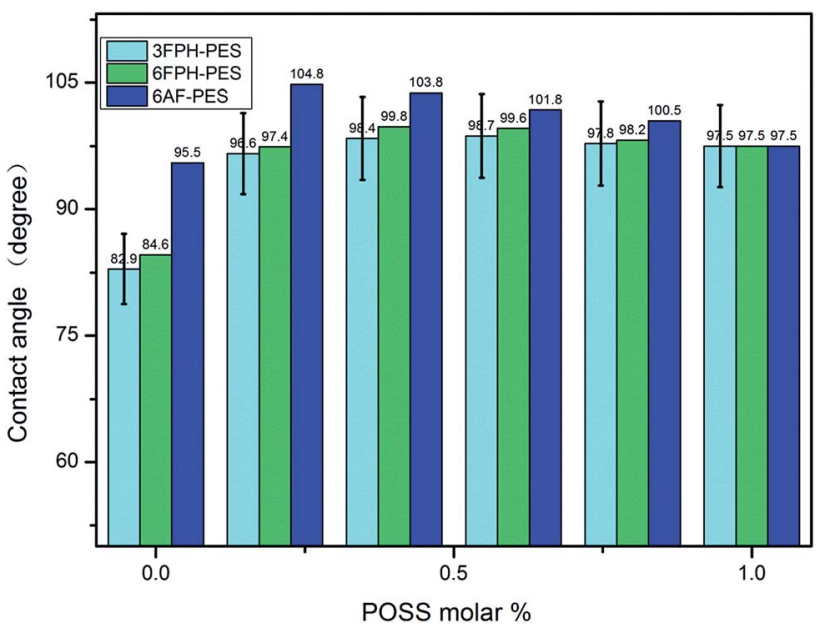

Fig. 5 Contact angle of DDSQ-CF $3-P E S s$ hybrids.

\section{Surface properties and solubility of polymers}

Contact angle is widely used to get information about the nature of surface properties of copolymers. In this study, the surface properties such as hydrophobicity and the polarizability of the polymers were evaluated (Fig. 5). Contact angle measurements showed that the PESs polymers containing $-\mathrm{CF}_{3}$ and POSS displayed a significant enhancement in surface hydrophobicity than that of pure PES $\left(\mathrm{CA}=80^{\circ}\right)$. Comparing three kinds of polymers, the contact angle at the same content of DDSQ represented the following law: DDSQ-6AF-PESs > DDSQ-6FPH-PESs > DDSQ3 FPH-PESs. On the one hand, owing to the introduction of low polar trifluoromethyl, hydrophobicity can be enhanced along with the content of trifluoromethyl increasing; on the other hand, the surface free energy of the DDSQ-6FPH-PESs and DDSQ3FPH-PESs may be increased due to the asymmetric substitutent of 3,5-ditrifluoromethylphenyl and trifluoromethylphenyl, which may lead to the deterioration of the hydrophobicity.

Table 2 Summaries of the properties of the DDSQ-6FPH-PESs

\begin{tabular}{llccccc}
\hline Samples & $\begin{array}{l}\text { Inherent } \\
\text { viscosity }\end{array}{ }^{a}\left(\mathrm{~g} \mathrm{dL}^{-1}\right)$ & $T_{\mathrm{d} 5}{ }^{b}\left({ }^{\circ} \mathrm{C}\right)$ & Residue $^{c}(\%)$ & $T_{\mathrm{g}}{ }^{d}\left({ }^{\circ} \mathrm{C}\right)$ & CA $(\mathrm{deg})$ & $\begin{array}{l}\text { Dielectric } \\
\text { constant }^{e}\end{array}$ \\
\hline PES 2b I & 0.76 & 550.0 & 0.943 & 164.4 & 84.6 & 3.14 \\
PES 2b II & 0.74 & 427.7 & 13.72 & 159.6 & 97.4 & 2.71 \\
PES 2b III & 0.76 & 426.8 & 26.67 & 156.4 & 99.8 & 2.23 \\
PES 2b IV & 0.73 & 422.6 & 32.22 & 154.3 & 99.6 & 2.36 \\
PES 2b V & 0.71 & 434.9 & 35.99 & 148.6 & 98.2 & 2.34 \\
Dielectric loss
\end{tabular}

${ }^{a}$ Determined at a concentration $0.5 \mathrm{~g} \mathrm{dL}^{-1}$ in DMAc at $25^{\circ} \mathrm{C} .{ }^{b}$ Temperature at which $5 \%$ weight loss was recorded by thermogravimetry at a heating rate of $10^{\circ} \mathrm{C} \mathrm{min}{ }^{-1}$ in air. ${ }^{c}$ The yields of degradation residues were obtained at $800{ }^{\circ} \mathrm{C}$ in air. ${ }^{d}$ DSC at a heating rate of $10^{\circ} \mathrm{C}$ min ${ }^{-1}$ in nitrogen. ${ }^{e} K$ was measured at $1 \mathrm{MHz} .{ }^{f}$ Dielectric loss was measured at $1 \mathrm{MHz}$. 
Table 3 Summaries of the properties of the DDSQ-6AF-PESS

\begin{tabular}{|c|c|c|c|c|c|c|c|}
\hline Samples & $\begin{array}{l}\text { Inherent } \\
\text { viscosity }^{a}\left(\mathrm{~g} \mathrm{dL}^{-1}\right)\end{array}$ & $T_{\mathrm{d} 5}^{b}\left({ }^{\circ} \mathrm{C}\right)$ & Residue $^{c}(\%)$ & $T_{\mathrm{g}}{ }^{d}\left({ }^{\circ} \mathrm{C}\right)$ & CA (deg) & $\begin{array}{l}\text { Dielectric } \\
\text { constant }^{e}\end{array}$ & Dielectric loss ${ }^{f}$ \\
\hline PES 2c I & 0.81 & 551.2 & 0.753 & 170.7 & 95.5 & 3.34 & 0.00118 \\
\hline PES 2c III & 0.81 & 444.5 & 23.22 & 162.2 & 103.8 & 2.7 & 0.00192 \\
\hline PES 2c IV & 0.79 & 422.4 & 30.61 & 158.2 & 101.3 & 2.67 & 0.00172 \\
\hline PES 2c V & 0.75 & 436.3 & 34.93 & 155.8 & 100.5 & 2.43 & 0.00121 \\
\hline
\end{tabular}

${ }^{a}$ Determined at a concentration $0.5 \mathrm{~g} \mathrm{dL}^{-1}$ in DMAc at $25^{\circ} \mathrm{C} .{ }^{b}$ Temperature at which $5 \%$ weight loss was recorded by thermogravimetry at a heating

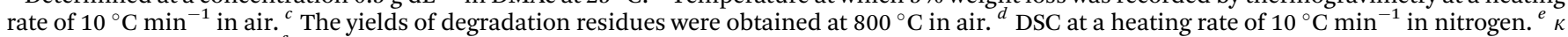
was measured at $1 \mathrm{MHz} .{ }^{f}$ Dielectric loss was measured at $1 \mathrm{MHz}$.

The contact angle experiments of three series of POSS containing polymers showed that the contact angles increased first and then decreased with the increase of DDSQ content. This is can be attributed that both low polar trifluoromethyl and low surface free energy POSS can help to enhance the hydrophobicity and the enhancement of the hydrophobicity of trifluoromethyl is larger than that of the POSS.

The best hydrophobicity can be obtained by the synergistic effect of the low polarity, low surface free energy of trifluoromethyl and POSS. The largest contact angle of DDSQ-3FPH-PESs is $98.7^{\circ}$ at $60 \%$ DDSQ-3FPH-PES; the DDSQ-6FPH-PESs is $99.8^{\circ}$ at $40 \%$ DDSQ-6FPH-PES; the DDSQ-6AF-PESs is $104.8^{\circ}$ at $20 \%$ DDSQ6AF-PES. To improve the hydrophobicity was also an effect approach to keep the stability of dielectric property. ${ }^{34,35}$

The solubility behavior of the polymers in some solvents is listed in Table 4 . All of the polymers prepared were soluble at room temperature in most aprotic polar solvents such as NMP, DMAc, DMF and DMSO. The polymers without DDSQ were soluble at room temperature in the less polar solvents such as chloroform and tetrahydrofuran (THF). Due to the presence of $\mathrm{CF}_{3}$ groups in the polymers, the solubility of these polymers was better than (that of) pure PES.

\section{Thermal properties}

The thermal stabilities of the copolymers were tested by TGA and the results were summarized in Tables 1-3 and the profiles

Table 4 Solubility of DDSQ-CF - PESs

\begin{tabular}{llllllll}
\hline Samples & NMP & DMAc & DMSO & DMF & THF & Chloroform & Acetone \\
\hline PES & ++ & ++ & +- & +- & -- & -- & -- \\
PES 2a I & ++ & ++ & ++ & ++ & ++ & ++ & ++ \\
PES 2a III & ++ & ++ & ++ & ++ & -- & -- & -- \\
PES 2a V & ++ & ++ & ++ & ++ & -- & -- & -- \\
PES 2a VI & ++ & +- & +- & +- & -- & -- & -- \\
PES 2b I & ++ & ++ & ++ & ++ & ++ & ++ & ++ \\
PES 2b III & ++ & ++ & ++ & ++ & -- & -- & -- \\
PES 2b V & ++ & ++ & ++ & ++ & -- & -- & -- \\
PES 2c I & ++ & ++ & ++ & ++ & ++ & ++ & ++ \\
PES 2c III & ++ & ++ & ++ & ++ & -- & -- & -- \\
PES 2c V & ++ & ++ & ++ & ++ & -- & -- & --
\end{tabular}

Solubility under a mass of liquid: $0.1 \mathrm{~g} \mathrm{~mL}^{-1} ;(++)$ soluble at room temperature; $(--)$ insoluble even on heating; $(+-)$ partially soluble or swelling on heating. were shown in Fig. 6. The polymers have excellent stabilities against thermal decomposition. The temperatures at a $5 \%$ weight loss $\left(T_{\mathrm{d} 5}\right)$ are above $410.7^{\circ} \mathrm{C}$. The copolymers without

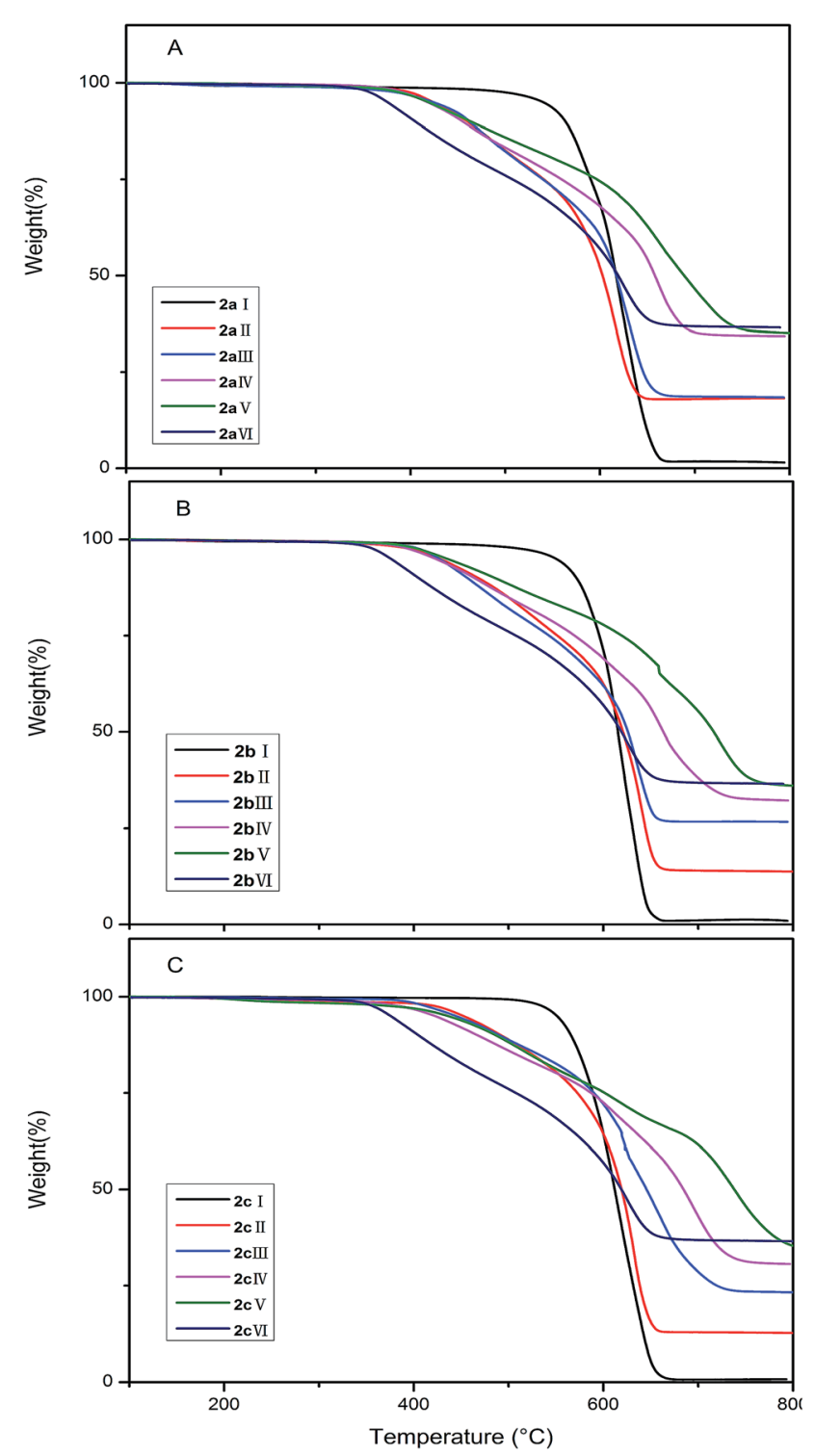

Fig. 6 TGA curves of DDSQ-CF - PESs hybrids in air. 
DDSQ represent one step degradation progress; the copolymers containing DDSQ represent two steps degradation progress: the first step is ascribed to the cleavage of flexible alkyl chain and the second step is ascribed to the decomposition of the aromatic ring and DDSQ cage frameworks.

The $T_{\mathrm{g}}$ of the three series of DDSQ- $\mathrm{CF}_{3}-\mathrm{PESs}$ copolymers decrease with the increase of POSS content. This is attributed to the increase of free volume through the introduction of bulky $\mathrm{CF}_{3}$ and the cage-like structure DDSQ.

Comparing three kinds of polymers, the $T_{\mathrm{g}}$ at the same content of DDSQ represented the following law: DDSQ-6AFPESs > DDSQ-6FPH-PESs > DDSQ-3FPH-PESs. On the one hand, the free volume of hexafluoroisopropyl group is smaller than bulky trifluoromethyl side group, therefore $T_{\mathrm{g}}$ of DDSQ6AF-PESs are higher than DDSQ-6FPH-PESs and DDSQ-3FPHPESs; on the other hand, the segment movement of 3,5-ditrifluoromethylphenyl is harder than trifluoromethylphenyl, resulting in the reduction of free volume and the increase of $T_{\mathrm{g}}$.

\section{Conclusions}

Three series of new aromatic poly(ether sulfones) (PESs) were prepared from 2OH-DDSQ, three bisphenol containing trifluoromethyl groups via the nucleophilic aromatic substitution polymerization. The resulting PESs are amorphous and exhibited outstanding thermostabilities in air. The variation of dielectric constant depends on the incorporation of the low polar of $\mathrm{CF}_{3}$ and vacant-cage structure POSS with large free volume, as well as the synergistic effect of DDSQ and trifluoromethyl. The enhancement of hydrophobicity attributes to the low polar substituent of $\mathrm{CF}_{3}$ and POSS with low surface free energy. In addition, three series of copolymers are made a contrast analysis, the results show that DDSQ-6FPH-PESs have lower dielectric constant, DDSQ-6AF-PESs have higher glass transition temperature and better hydrophobicity.

\section{References}

1 P. J. Jones and R. D. Cook, J. Appl. Polym. Sci., 2011, 121, 2945-2956.

2 S. Papadimitriou, D. N. Bikiaris and K. chrissafis, J. Polym. Sci., Part A: Polym. Chem., 2007, 45, 5076-5090.

3 Y. Ni and S. Zheng, Macromolecules, 2007, 40, 7009-7018.

4 S. Chisca, L. Sava and M. Bruma, Polym. Int., 2013, 62, 16341643.

5 K. Nagai, A. Takahashi, M. Suzuki and A. Mukoh, J. Appl. Polym. Sci., 1992, 44, 159-164.

6 J. Li, H. S. Zhang and F. Liu, Polymer, 2013, 54, 5673-5683.

7 W. L. Volksen, R. D. Miller and G. Dubois, Chem. Rev., 2010, 110, 56-110.

8 X. L. Liu, H. X. Yang and J. G. Liu, J. Appl. Polym. Sci., 2015, 132, 42358-42366.
9 G. Maier, Prog. Polym. Sci., 2001, 26, 3-65.

10 B. J. Liu, W. Hu and C. H. Chen, Polymer, 2004, 45, 32413247.

11 S. Ghosh and S. Banerjee, J. Membr. Sci., 2014, 470, 535-546.

12 G. M. Whitesides, J. P. Mathias and C. T. Seto, Science, 1991, 254, 1312-1319.

13 C. Sanchez, B. Julian, P. Belleville and M. Popall, J. Mater. Chem., 2005, 15, 3559-3592.

14 H. Xu, S. Kuo, J. Lee and F. Chang, Macromolecules, 2002, 35, 8788-8793.

15 M. E. Wright and D. A. Schorzman, Chem. Mater., 2003, 15, 264-268.

16 Y. J. Lee, J. M. Huang and S. W. Kuo, Polymer, 2005, 46, 173181.

17 C. Leu, Y. Chang and K. Wei, Chem. Mater., 2003, 15, 37213727.

18 A. Lee and J. D. Lichtenhan, Macromolecules, 1998, 31, 49704974.

19 J. Choi, J. Harcup and A. F. Yee, J. Am. Chem. Soc., 2001, 123, 11420-49430.

20 S. Turri and M. Levi, Macromol. Rapid Commun., 2005, 26, 1233-1236.

21 M. E. Wright, D. A. Schorzman and F. J. Feher, Chem. Mater., 2003, 15, 264-268.

22 K. Ohno, S. Sugiyama and K. Koh, Macromolecules, 2004, 37, 8517-8522.

23 C. Zhang, F. Babonneau and C. Bonhomme, J. Am. Chem. Soc., 1998, 120, 8380-8391.

24 M. J. Abad, L. Barral and D. F. Fasce, Macromolecules, 2003, 36, 3128-3135.

25 W. H. Zhang, J. D. Xu, X. S. Li, G. H. Song and J. X. Mu, J. Polym. Sci., Part A: Polym. Chem., 2014, 52, 780-788.

26 K. Wei, L. Wang and S. X. Zheng, Polym. Chem., 2013, 4, 1491-1501.

27 J. D. Xu, W. H. Zhang, Q. Y. Jiang and J. X. Mu, Polymer, 2015, 62, 77-85.

28 S. M. Wu and T. Hayakawa, Macromolecules, 2007, 40, 56985705.

29 S. M. Wu and T. Hayakawa, Macromolecules, 2008, 41, 34813487.

30 B. J. Liu, G. B. Wang, W. Hu and Y. H. Jin, J. Polym. Sci., Part A: Polym. Chem., 2002, 40, 3392-3398.

31 T. Hirai, M. Leolukman, S. Jin and R. Goseki, Macromolecules, 2009, 42, 8835-8843.

32 S. Jin, T. Hira, B. Ahn and Y. Rho, J. Phys. Chem. B, 2010, 114, 8033-8042.

33 Y. Chen and E. T. Kang, Mater. Lett., 2004, 58, 3716-3719.

34 C. Leu, G. M. Reddy and K. Wei, Chem. Mater., 2003, 15, 2261-2265.

35 Y. J. Shieh, C. Y. Lin and C. L. Huang, J. Appl. Polym. Sci., 2006, 101, 342-347. 